\title{
Preliminary EOF Analysis of the F Component at Geomagnetic Stations
}

Conference Paper · August 2009

DOI: 10.1190/sbgf2009-375

CITATIONS

0

4 authors:

8

Virginia Klausner

Universidade do Vale do Paraíba

43 PUBLICATIONS 161 CITATIONS

SEE PROFILE

Andres R. R. Papa

Observatório Nacional

62 PUBLICATIONS 257 CITATIONS

SEE PROFILE
Odim Mendes

National Institute for Space Research, Brazil 132 PUBLICATIONS 537 CITATIONS

SEE PROFILE

Margarete O. Domingues

National Institute for Space Research, Brazil

144 PUBLICATIONS 532 CITATIONS

SEE PROFILE

Some of the authors of this publication are also working on these related projects:

MHD in Space Sciences View project

Mixed Fourier and wavelet analysis of geomagnetic data View project 


\section{Preliminary EOF Analysis of the F Component at Geomagnetic Stations}

Virginia Klausner, Observatório Nacional/ON and CEA/DGE/INPE, Brazil

Odim Mendes Jr, CEA/DGE/INPE, Brazil

Andrés R. R. Papa, Observatório Nacional/ON and State University of Rio de Janeiro/UERJ, Brazil

Margarete Oliveira Domingues, CTE/LAC/INPE, Brazil

Copyright 2009, SBGf - Sociedade Brasileira de Geofísica

This paper was prepared for presentation during the $11^{\text {th }}$ International Congress of the Brazilian Geophysical Society held in Salvador, Brazil, August 24-28, 2009.

Contents of this paper were reviewed by the Technical Committee of the $11^{\text {th }}$ International Congress of the Brazilian Geophysical Society and do not necessarily represent any position of the SBGf, its officers or members. Electronic reproduction or storage of any part of this paper for commercial purposes without the written consent of the Brazilian Geophysical Society is prohibited.

\section{Abstract}

Empirical orthogonal functions (EOFs) are used to study a time-series of the total geomagnetic field for seven different magnetic stations to determine the dominant patterns of the geomagnetic field variance. A five-day interval from 13 to 17 of July, 2000 was used in the study. EOFs analysis decomposed the time series into its component parts. The magnetic stations considered in the analysis were: Fredericksburg, Boulder, Tucson, Memambetsu, Martin de Vivies, Chambon-la-Forêt and Vassouras.

\section{Introduction}

By international agreement, the Earth's field components are described by the "right-hand system". It means that the $x$ direction would be indicated by our thumb, the $y$ direction by our pointing finger and the $z$ direction by the remaining fingers. However, the Earth's field can be described in two ways: (1) three orthogonal component field called the $X, Y$ and $Z$ representation or (2) the horizontal magnitude, $\mathrm{H}$, the eastward angular direction of the horizontal component from geographic northward, D, and the downward component, $\mathrm{Z}$, called the $\mathrm{H}$ (horizontal), D (declination) and $\mathrm{Z}$ (vertical) representation. Figure 1 illustrates these nomenclatures for a location in the Northern Hemisphere where the total field vector points into the Earth (Campbell, 1997).

The geomagnetic field is a complicated function of space and time. Ground based magnetic measurements show a repetitive diurnal variation on geomagnetically quiet days (Tascione, 1988). But there is a great variety of irregular variations that occur from time to time, the "disturbance fields". Periods of great disturbance are called, by analogy with the weather, "magnetic storms" (Parkinson, 1983).

The primary causes of geomagnetic storms at Earth are strong dawn-to-dusk electric field associated with the passage of southward directed interplanetary fields, Bs, passing the Earth for sufficiently long intervals of time (more than 3 hours). The solar wind energy transfer mechanism is magnetic reconnection between the interplanetary magnetic field and the Earth's magnetic field (Gonzalez et al., 1994).
The magnetic field measured at mid-to-low latitudes can be affected significantly by variations of the solar wind ram pressure, which produces changes in the magnetopause current. This process gives place to a storm sudden commencement (SSC), when an increase in the horizontal magnetic field is observed at mid-to-low latitudes (Mendes Jr. et al., 2005). The characteristic signature of a magnetic storm is a depression in the horizontal component of the Earth's magnetic field due to changes of the ring current (Gonzalez et al., 1994).

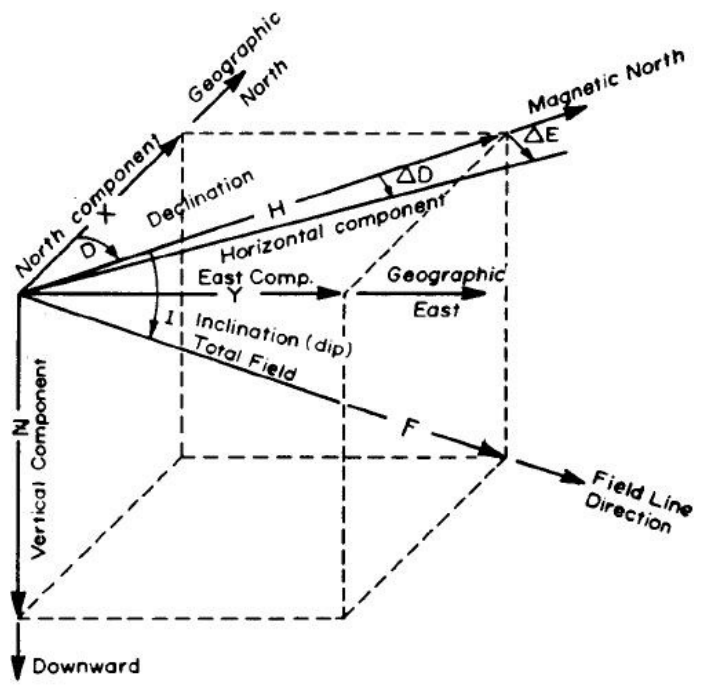

Figure 1: Components of geomagnetic field measurements. Source: Campbell, 1997.

Asymmetric (ASY) and symmetric disturbance indexes describe the geomagnetic disturbance field in midlatitudes with high-time resolution. These indexes are derived for both $\mathrm{H}$ and $\mathrm{D}$ components, that is, for the components in the horizontal (dipole pole) direction $\mathrm{H}$ (SYM-H, ASY-H) and in the orthogonal (East-West) direction D (SYM-D, ASY-D). These indexes are calculated by averaging the disturbance component at each minute (Fredericksburg, Boulder, Tucson, Memambetsu, Martin de Vivies and Chambon-la-Forest). Some of these stations can be eventually replaced by others depending on the availability and the condition of the data of the month (WDC-Kyoto, 2008).

The purpose of this work is to study the variance of the data sets from the six stations, employed to calculate asymmetric and symmetric indexes, using the empirical orthogonal function (EOF) analysis. Other purpose is also, to include in the analysis the Vassouras station to obtain a new variance in order to evaluate the feasibility 
or not of this station as a candidate to enter the calculation of asymmetric and symmetric indexes.

\section{Empirical Orthogonal Function Analysis}

Among the several available methods of analysis, EOF is a particularly useful tool in studying large quantities of multi-variate data. EOF analysis is used to decompose a time-series into its orthogonal component modes, the first of which can be used to describe the dominant patterns of variance in the time series (see e.g. Keiner and Yan, 1997).

EOFs are derived as the eigenvectors of the covariance matrix between the variables. Their form depends directly on the interrelationships existing within the data itself. The first EOF is the linear combination of the original variables, which when used as a linear predictor of these variables, explain the largest fraction of the total variance. The second, third EOF, etc., explain the largest parts of the remaining variance (Murray et al., 1984).

Consider $\mathrm{M}$ variables $x_{m}(t)$, which might represent the geomagnetic observations at $M$ stations as functions of time. Let these be observed at $N$ times, $i=1,2, \ldots, n$. We can construct the $m \times n$ matrix as follows:

$$
X=\left[\begin{array}{ccc}
x_{11} & \cdots & x_{1 m} \\
\vdots & 1 & \vdots \\
x_{n 1} & \cdots & x_{n m}
\end{array}\right]
$$

The center of gravity of the $m$ points is $\bar{x}$ where the ith coordinate is

$$
\overline{x_{1}}=\frac{1}{m} \sum_{j=1}^{m} x_{i j}
$$

The points measured from their center of gravity, $v_{i j}=\left(x_{i j}-\bar{x}_{i}\right)$ can be written

$$
V=\left[\begin{array}{ccc}
v_{11} & \cdots & v_{1 \mathrm{~m}} \\
v_{\mathrm{n} 1} & \cdots & v_{\mathrm{mm}}
\end{array}\right]
$$

We obtain the EOFs as the eigenvectors of the covariance matrix $C$

$$
C=\frac{1}{N-1}\left[V V^{T}\right]
$$

We can summarize several properties of $C$ (Shlens, 2005):

- $\quad c$ is a square symmetric $m \times m$ matrix.

- The diagonal terms of $c$ are the variances of particular measurements types.

- The off-diagonal terms of $c$ are the covariance between measurement types.

A property of EOF's which make them particularly appealing is that, unlike more conventional orthogonal representations (as, for example, Fourier decomposition, Tschebycheff polynomials and spherical harmonics) they do not require any predetermined form (Murray et al., 1984).

\section{The data base}

In this paper, we used magnetic ground measurements to study the variance between different magnetic stations. We choose seven stations that belong to the INTERMAGNET programme. The stations considered in this analysis are: Fredericksburg, Boulder, Tucson, Memambetsu, Martin de Vivies, Chambon-la-Forêt and Vassouras. The geographic and geomagnetic coordinates and elevation of these magnetic stations are given in Table 1.

In order to develop this analysis, one hour time resolution magnetograms obtained at these seven stations were used. The datasets have been downloaded from the INTERMAGNET CD-ROM (vol 2, 2000). A five-day interval of the total geomagnetic field was considered as dataset.

The period of analysis is from 13 to 17 of July, 2000 . During these days occurred a very intense storm or superstorm. This storm started on July 15, 2000 and the main phase reached a minimum Dst $=-301 \mathrm{nT}$ at 01:00 UT on July 16, 2000. Figure 2 show the Dst index for the whole month of July that belong to solar cycle 23 (period of solar maximum).

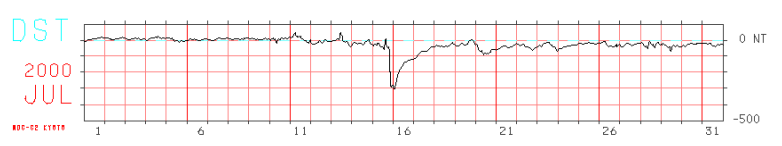

Figure2: Dst index for July, 2000.

\section{Methodology}

The methodology to process the magnetograms was based on the following steps:

(1) The data set was organized as an $m \times n$ matrix, where $m$ is the number of stations and $n$ is the time series of the total geomagnetic field observations for five-day interval with 1 hour time resolution.

(2) The mean $\left(x_{i \xi}\right)$ was subtracted off for each row of observation.

(3) The correlation matrix between the stations was calculated.

(4) The eigenvectors of the covariance matrix were calculated (Principal Components).

The first eigenvectors of EOF represent the mostly the variability associated with the magnetic station which are characterized by a higher variance. In this analysis, we choose the first three principal components (PC) because they contained most of the variance.

The analysis was performed for two data sets. The first dataset was using only the data from the stations that enter the calculation of asymmetric and symmetric indexes (six stations). The second dataset was the first dataset plus the data from the Vassouras station.

\section{Results and discussion}

In this section, we will discuss the EOF analysis for both datasets focusing first in the six stations and after that in the seven stations. In Figure 3, we show the correlation matrix between the stations: Fredericksburg, Boulder Tucson, Memambetsu, Martin de Vivies and Chambon-laForêt. In Figure 4, we show the correlation matrix between those six stations plus Vassouras station. The correlation matrix lists each of the stations down in the column and across in the row. So the first column 
represents the station of Fredericksburg, the second, the station of Boulder and so on. The same happens for the rows. The diagonal of the correlation matrix always consists of ones. That's because these are the correlations between each variable and itself (and a variable is always perfectly correlated with itself). To locate the correlation for any pair of station, find the value in the table for the row and column intersection for those two stations. The correlation will always be between -1 and 1.

$$
\begin{array}{|cccccc|}
1.0000 & 0.7484 & -0.8280 & -0.8427 & -0.8991 & -0.5161 \\
0.7484 & 1.0000 & -0.4226 & -0.8229 & -0.8991 & -0.5161 \\
-0.8280 & -0.4226 & 1.0000 & 0.6994 & 0.5842 & 0.0943 \\
-0.8427 & -0.8229 & 0.6994 & 1.0000 & 0.7665 & 0.3079 \\
-0.8991 & -0.8705 & 0.5842 & 0.7665 & 1.0000 & 0.5526 \\
-0.5161 & -0.6230 & 0.0943 & 0.3079 & 0.5526 & 1.0000
\end{array} \mid
$$

Figure 3: The correlation matrix between the six stations. The rows and columns correspond to the stations of Fredericksburg, Boulder Tucson, Memambetsu, Martin de Vivies and Chambon-la-Forêt, respectively.

$$
\begin{array}{lllllll}
1.0000 & 0.8088 & -0.7049 & -0.8242 & -0.8512 & -0.1987 & -0.8447 \\
0.8088 & 1.0000 & -0.2845 & -0.8331 & -0.8512 & -0.1987 & -0.8376 \\
-0.7049 & -0.2845 & 1.0000 & 0.4855 & 0.3825 & -0.1957 & 0.5269 \\
-0.8242 & -0.8331 & 0.4855 & 1.0000 & 0.6756 & 0.0115 & 0.8015 \\
-0.8512 & -0.8297 & 0.3825 & 0.6756 & 1.0000 & 0.3554 & 0.6352 \\
-0.1987 & -0.2823 & -0.1957 & 0.0115 & 0.3554 & 1.0000 & -0.0941 \\
-0.8447 & -0.8376 & 0.5269 & 0.8015 & 0.6352 & -0.0941 & 1.0000
\end{array}
$$

\begin{tabular}{|c|c|c|c|}
\hline $\begin{array}{c}\text { ABB } \\
\text { CODE }\end{array}$ & $\begin{array}{c}\text { EOF } \\
1 \\
\end{array}$ & $\begin{array}{c}\text { EOF } \\
2 \\
\end{array}$ & $\begin{array}{c}\text { EOF } \\
3 \\
\end{array}$ \\
\hline FRD & -0.4655 & -0.1204 & 0.3002 \\
\hline $\mathrm{BOU}$ & -0.4290 & 0.2111 & -0.5639 \\
\hline TUC & 0.3544 & 0.5815 & -0.4627 \\
\hline MMB & 0.4349 & 0.2020 & 0.3639 \\
\hline AMS & 0.4530 & -0.1151 & 0.0890 \\
\hline CLF & 0.2800 & -0.7407 & -0.4873 \\
\hline
\end{tabular}

Figure 4: The correlation matrix between the seven stations. The rows and columns correspond to the stations of Fredericksburg, Boulder Tucson, Memambetsu, Martin de Vivies, Chambon-la-Forêt and Vassouras, respectively.

Table 2. The three first EOFs for the six stations.

Figure 5 shows the pattern for the first most important EOFs calculated for the six stations that compound the asymmetric and symmetric indexes (Fredericksburg, Boulder, Tucson, Memambetsu, Martin de Vivies and
Chambon-la-Forêt). The values for the three first principal components are shown in Table 2.

We observe that the spatial pattern for the first EOF presents the same phase oscillation for almost all magnetic stations except for the FRD and BOU stations. The EOFs lower amplitudes belong to the CLF and TUC stations. The second EOFs present similar oscillations between the FRD and AMS; and also between BOU and MMB. The larger amplitude is present by CLF and TUC. The third EOF present quite dissimilar pattern, only the TUC and CLF stations present quite the same amplitude and phase oscillation.

Figure 6 is similar to Figure 5, but shows the spatial pattern of the first EOF for the same six stations plus the Vassouras station. Also, in Table 3 the spatial patterns of the three first principal components for the stations, mentioned above, are given.

After including the Vassouras station, we verify in the first EOF that FRD and BOU are oscillating in phase opposition with MMB, AMS and VSS. The lower amplitudes are present by CLF and TUC. For the second

\begin{tabular}{|c|c|c|c|}
\hline $\begin{array}{c}\text { ABB } \\
\text { CODE }\end{array}$ & $\begin{array}{c}\text { EOF } \\
1\end{array}$ & $\begin{array}{c}\text { EOF } \\
2 \\
\end{array}$ & $\begin{array}{c}\text { EOF } \\
3\end{array}$ \\
\hline FRD & 0.4568 & -0.0070 & -0.2481 \\
\hline $\mathrm{BOU}$ & 0.4292 & 0.1723 & 0.3804 \\
\hline TUC & -0.2870 & 0.4580 & 0.7153 \\
\hline MMB & -0.4212 & 0.0802 & -0.2451 \\
\hline AMS & -0.4058 & -0.2762 & 0.0818 \\
\hline CLF & -0.0735 & -0.8030 & 0.3783 \\
\hline VSS & -0.4211 & 0.1819 & -0.2687 \\
\hline
\end{tabular}
EOF, CLF and TUC have the larger amplitudes of oscillation, respectively. The third EOF shows quite dissimilar patterns, but FRD, MMB and VSS are oscillating in phase with similar amplitudes. Also, BOU and CLF are oscillating in phase with similar amplitudes.

Table 3. The three first EOFs for the six stations plus Vassouras station.

\section{Final Remarks}

The EOF technique is a very useful method for compacting large data sets and for diagnosing the dominant patterns of variability in geophysical data sets.

The main conclusions in this analysis can be summarized as follow:

- For the first EOF, for the two sets of data, BOU and FRD were oscillating in opposition of phase with the rest of the stations.

- For the second EOF, in the two sets of data, TUC and CLF presented the larger amplitude of oscillation.

- The third EOF showed quite dissimilar patterns for the two datasets. 
The results suggest that EOFs can be used to characterize the statistical relationships between magnetic stations, but need further study.

\section{Acknowledgments}

This project is progressed with a collaboration between Instituto Nacional de Pesquisas Espaciais (INPE) and Observatório Nacional (ON). The authors wish to thank CAPES for the financial support and INTERMAGNET programme for the datasets used in this work.

\section{References}

Campbell W. H., 1997, Introduction to geomagnetic fields, Cambridge University Press, Cambridge, UK.

Gonzalez, W. D., J. A. Joselyn, Y. Kamide, H. W. Kroehl, G. Rostoker, B. T. Tsurutani and V. M. Vasyliunas, 1994, What is a geomagnetic storm?, Journal of Geophysical Research, vol 99, NO. A4, pages $5771-5792$

Keiner, L. E., and X. H. Yan, 1997, Empirical Orthogonal Function Analysis of Sea Surface Temperature Patterns in Delaware Bay, IEEE Transactions on Geoscience and Remote Sensing, vol 35, NO. 5.

Mendes Jr., O., M. O. Domingues, A. Mendes da Costa and A. L. C. Gonzalez, 2005, Wavelet analysis applied to magnetograms: Singularity detections related to geomagnetic storms, Journal of Atmospheric and SolarTerrestrial Physics, vol 67, pages $1827-1836$.

Murray, G. W., J. C. Muller and H. J. Zwally, 1984, Matrix portioning and EOF/Principal Components Analysis of Antartic Sea Ice Brightness Temperatures, Technical Notes NOAA.

Parkinson W. D., 1983, Introduction to geomagnetism, Scottish Academic Press Ltd., Edinburgh and London, UK.

Shlens J., 2005, A tutorial on Principal Component Analysis, http://www.snl.salk.edu/ shlens/pub/notes/pca. pdf.

Tascione T. F., 1988, Introduction to the space environment, Orbit Book Company, INC., Florida, USA.

WDC-Kyoto, 2008, http://swdcwww.kugi.kyoto-u.htmlu. ac.jp/index.html 
Table 1. Magnetic stations considered in the analysis.

\begin{tabular}{|c|c|c|c|c|c|}
\hline STATION NAME & $\begin{array}{c}\text { ABB } \\
\text { CODE }\end{array}$ & $\begin{array}{c}\text { Geo } \\
\text { LAT }\end{array}$ & $\begin{array}{c}\text { Geo } \\
\text { LOG }\end{array}$ & $\begin{array}{c}\text { Geo Mag } \\
\text { LAT }\end{array}$ & $\begin{array}{c}\text { ELEVATION } \\
(\mathrm{m})\end{array}$ \\
\hline Fredericksburg & FRD & 38.20 & -77.37 & 48.4 & 69 \\
\hline Boulder & BOU & 40.13 & -105.23 & 48.4 & 1682 \\
\hline Tucson & TUC & 32.17 & -110.73 & 39.94 & 946 \\
\hline Memambetsu & MMB & 43.91 & 144.19 & 35.35 & 42 \\
\hline Martin de Vivies & AMS & -37.80 & 77.57 & -46.40 & 50 \\
\hline Chambon-la-Forêt & CLF & 48.03 & 2.26 & 49.84 & 145 \\
\hline Vassouras & VSS & -22.40 & -43.65 & -13.29 & 460 \\
\hline
\end{tabular}

Source: http://swdcwww.kugi.kyoto-u.ac.jp/wdc/obsdata.html (2009)

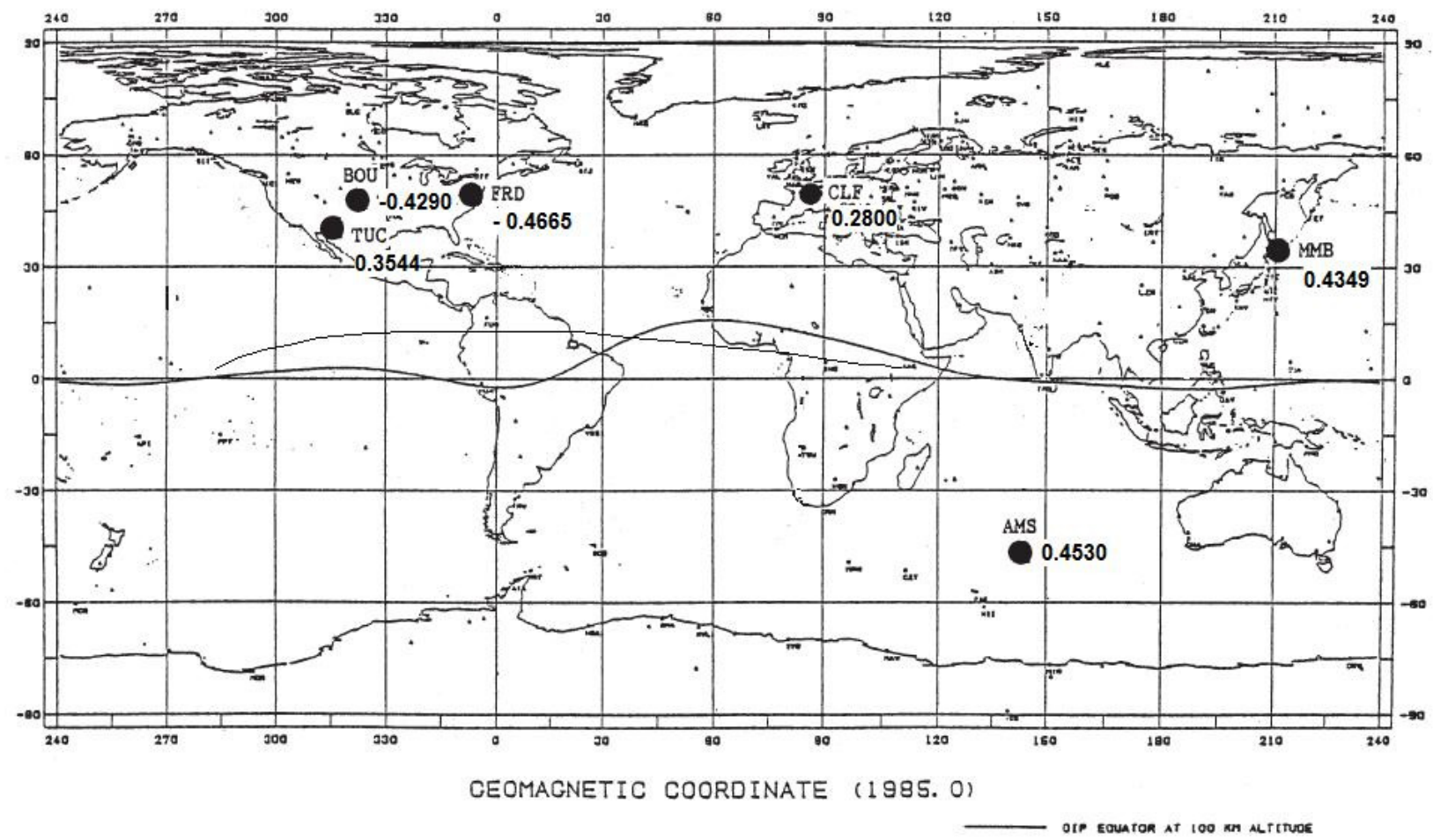

Figure 5: The spatial pattern of the first principal component for six magnetic stations.

Source: Modify from WDC-Kyoto (1999) 


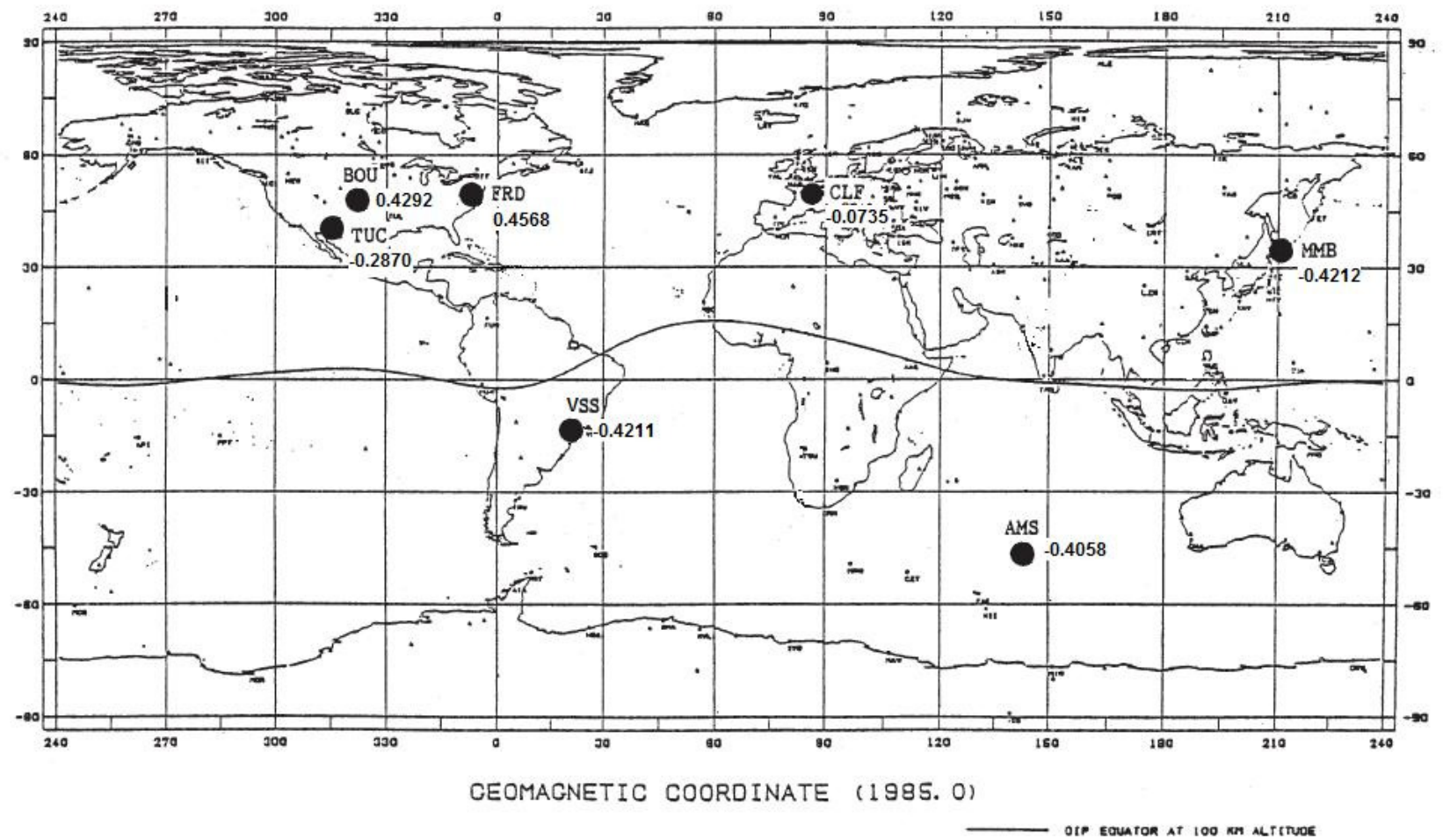

Figure 6: The spatial pattern of the first principal component for six magnetic stations plus the Vassouras station. Source: Modify from WDC-Kyoto (1999) 